\title{
Effects of the economical profitability of chemical control of leaf beetles (Oulema spp.) in spring wheat
}

\author{
Efekty produkcyjne i ekonomiczne zwalczania skrzypionek \\ (Oulema spp.) w pszenicy jarej
}

\section{Zdzisław Kaniuczak}

\section{Summary}

The research on production and economic effects of insect control in spring wheat was conducted in Boguchwała in the years 2011-2012. During that time cereal leaf beetle larvae damaged from 51.1 to $68.0 \%$ of the leaf surface. Each applied combination of studied insecticides recommended for spring wheat protection against insects contributed to significant reduction in their number and harmfulness. The insecticides used to control Oulema spp. larvae showed a good effectiveness ranging from 36.7 to $94.1 \%$. The production value saved due to plant protection treatments ranged from 51 to $603 \mathrm{PLN} / \mathrm{ha}, 240 \mathrm{PLN} / \mathrm{ha}$ on average. Costs of one hectare of spring wheat protection against cereal leaf beetle larvae was low, and ranged from 87 to 1.267 PLN per ha. The contribution ratio varied depending on the research year, ranging from 0.1 to 6.9. The treatment profitability ratio was 5.0 on average.

Key words: spring wheat, cereal leaf beetle, chemical control, economic indicators

\section{Streszczenie}

Badania nad efektami produkcyjnymi i ekonomicznymi zwalczania szkodników w pszenicy jarej wykonano w latach 2011-2012 w Boguchwale. W tym czasie larwy skrzypionek uszkodziły od 51,1 do 68,0\% powierzchni blaszek liściowych. Każda z zastosowanych kombinacji ochrony pszenicy jarej przed szkodnikami z wykorzystaniem badanych insektycydów przyczyniła się do istotnego ograniczenia ich liczebności i szkodliwości. Zastosowane insektycydy do zwalczania larw Oulema spp. wykazały dobrą skuteczność owadobójczą zawierającą się w przedziale od 36,7 do 94,1\%. Wielkość produkcji uratowanej w wyniku stosowania zabiegów ochrony roślin wahała się od 51 do 603 PLN/ha, średnio 240 PLN/ha. Koszt ochrony jednego hektara pszenicy jarej przed larwami skrzypionek był niski i wynosił od 87 do 1267 PLN/ha. Wskaźnik pokrycia kosztów wahał się w zależności od roku prowadzonych badań od 0,1 do 6,9. Wskaźnik opłacalności zabiegów wyniósł średnio 5,0.

Słowa kluczowe: pszenica jara, skrzypionki, ochrona chemiczna, wskaźniki ekonomiczne

\footnotetext{
Instytut Ochrony Roślin - Państwowy Instytut Badawczy

Terenowa Stacja Doświadczalna

Langiewicza 28, 35-101 Rzeszów

z.kaniuczak@iorpib.poznan.pl
} 


\section{Wstęp / Introduction}

Pszenica jest szeroko wykorzystywanym gospodarczo gatunkiem zbóż. Ochrona tej rośliny przed agrofagami jest jednym $\mathrm{z}$ podstawowych zabiegów niejednokrotnie decydującym o powodzeniu produkcji. Podczas wzrostu gatunek ten, jak i inne zboża, narażone są na znaczne straty powodowane przez szkodliwe owady (Miczulski 1973; Bubniewicz i wsp. 1993; Kaniuczak 1993; Mrówczyński i wsp. 2007; Kaniuczak 2011). Na wielkość plonów ziarna szczególnie negatywny wpływ mają: skrzypionki, mszyce, pryszczarki, miniarki, wciornastki, występujące w okresie od kłoszenia do dojrzałości mlecznej ziarniaków (Miętkiewski i wsp. 1991; Kaniuczak i Lisowicz 1992; Wałkowski i Złotkowski 2000; Mrówczyński i wsp. 2005).

Zagrożeniem powodujących straty gospodarcze w plonach zbóż są między innymi szkodniki, które w ciagu okresu wegetacji uszkadzają przede wszystkim nadziemne części roślin, głównie liście i kłosy. Najważniejszymi szkodnikami występującymi na zbożach w naszym kraju są skrzypionki i mszyce (Kaniuczak 1987, 1997; Mrówczyński i wsp. 2005; Kaniuczak i Bereś 2008).

Coroczne uszkadzanie roślin pszenicy przez larwy skrzypionek powoduje redukcję powierzchni blaszek liściowych, a w konsekwencji powoduje znaczne straty w plonach ziarna oraz pogorszenie jego jakości. Należy więc prowadzić coroczne obserwacje i analizy uzyskiwanych efektów ekonomicznych wykonywanych zabiegów ochrony roślin (Jańczak i wsp. 1990; Kaniuczak i Matłosz 1999; Lipa 1999; Wałkowski i Złotkowski 2000).

Celem badań była dwuletnia ocena skuteczności wybranych do doświadczeń sześciu insektycydów oraz ocena efektywności ekonomicznej zastosowanych insektycydów w zwalczaniu skrzypionek.

\section{Materiały i metody / Materials and methods}

Badania przeprowadzono w latach 2011-2012, w uprawie pszenicy jarej, odmiana Bombona, w Podkarpackim Ośrodku Doradztwa Rolniczego w Boguchwale (49 $59^{\prime}$ N; $21^{\circ} 57^{\prime}$ E). Doświadczenia założono metodą bloków losowanych w czterech powtórzeniach. Siew pszenicy wykonano na glebie brunatnej, klasy IIIa. Przedplonem był rzepak ozimy. Zgodnie z zaleceniami Instytutu Uprawy Nawożenia i Gleboznawstwa - Państwowego Instytutu Badawczego i Instytutu Ochrony Roślin - Państwowego Instytutu Badawczego wykonano zabiegi agrotechniczne i chwastobójcze. Siew ziarna przeprowadzono w pierwszych dniach kwietnia, wysiewając 500 ziaren $/ \mathrm{m}^{2}$. Ziarno zaprawiono zaprawą Sarfun T 65 DS (karboksyna 37,5 g/l, tiuram 37,5 g/l) w dawce $200 \mathrm{~g} / 100 \mathrm{~kg}$. Stosowano następujące nawożenie: $\mathrm{N}-120 \mathrm{~kg} / \mathrm{ha}, \mathrm{P}_{2} \mathrm{O}_{5}-60 \mathrm{~kg} / \mathrm{ha}$, $\mathrm{K}_{2} \mathrm{O}-90 \mathrm{~kg} / \mathrm{ha}$. Zwalczanie chwastów wykonano środkami: w latach 2011-2012 - Lintur 70 WG (dikamba $65,9 \mathrm{~g} / \mathrm{l}$, triasulfuron $4,1 \mathrm{~g} / \mathrm{l}) \mathrm{w}$ dawce $0,15 \mathrm{l} / \mathrm{ha}+$ Chwastox Extra 300 SL (MCPA $300 \mathrm{~g} / \mathrm{l}$ ) w dawce 1,5 1/ha.

Obserwacjami i analizami objęto larwy skrzypionki zbożowej (Oulema melanopa L.) i skrzypionki błękitek (Oulema cyanella Voet.). Nasilenie występowania skrzy- pionek analizowano podczas wegetacji zbóż zgodnie z metodą opisaną przez Kaniuczaka i wsp. (1992).

$\mathrm{W}$ fazie wzrostu roślin, $\mathrm{w}$ okresie otwierania się pochwy liścia flagowego $\mathrm{BBCH}$ 45-49 (Adamczewski i Matysiak 2002) użyto do zwalczania larw skrzypionek następujące insektycydy: Karate 050 CS (lambda-cyhalotryna $50 \mathrm{~g} / \mathrm{l}$ ) w dawce $0,1 \mathrm{l} / \mathrm{ha}$, Sumi-Alpha $050 \mathrm{EC}$ (esfenwalerat $50 \mathrm{~g} / \mathrm{l}$ ) w dawce 0,25 1/ha, Fastac $100 \mathrm{EC}$ (alfa-cypermetryna $100 \mathrm{~g} / \mathrm{l}$ ) $\mathrm{w}$ dawce $0,1 \mathrm{l} / \mathrm{ha}$ oraz Biospin $120 \mathrm{SC}$ (spinosad $120 \mathrm{~g} / \mathrm{l}$ ) w dawce 1,5 1/ha, NeemSAzal + Trifolio S-Forte (azadirachtin)] w dawce 2,5 1/ha oraz Novodor SC (Bacillus thuringiensis 2,4) w dawce 5,0 1/ha.

Zabiegi wykonano przy użyciu opryskiwacza, stosując $300 \mathrm{dm}^{3}$ cieczy na hektar. Ocenę szkodliwości skrzypionek wykonano określając procent uszkodzenia powierzchni dwóch górnych liści: flagowego i podflagowego na 100 źdźbłach z każdej kombinacji doświadczalnej. Po osiągnięciu przez rośliny dojrzałości pełnej, przeprowadzono zbiór ziarna kombajnem poletkowym. Oznaczono wilgotność ziarna i otrzymane plony przeliczano na $15 \%$ wilgotności. Istotność różnic pomiędzy średnimi oceniano testem Duncana przy 5\% poziomie istotności.

W analizie ekonomicznej opłacalności chemicznego zwalczania szkodników wyliczono następujące wskaźniki: $\mathrm{W}_{\mathrm{pk}}$ - wskaźnik pokrycia kosztów (określający stosunek wartości produkcji uratowanego plonu do kosztów zabiegu insektycydowego), $\mathrm{E}_{1}$ - wskaźnik opłacalności zabiegów (który określa liczbę dt produktu chronionego równoważącego koszty zabiegów ochronnych), $\mathrm{E}_{2}$ - procentowy wskaźnik kosztów (stanowiący procent plonu plantacji chronionej, który należy przeznaczyć na zrównoważenie kosztów zabiegów ochronnych) (Golinowska 2009). Do obliczenia wyżej wymienionych wskaźników przyjęto średnie ceny ziarna pszenicy, zastosowanych środków ochrony roślin oraz koszt ochrony.

\section{Wyniki i dyskusja / Results and discussion}

Przebieg warunków meteorologicznych w tych częściach okresu wegetacji, w których wywierały one największy wpływ na zdrowotność pszenicy w latach 2011-2012 przedstawiono w tabeli 1.

W 2011 roku pomimo wiosennych chłodów i opadów deszczu, w maju i czerwcu nastąpiła wyraźna poprawa pogody, która sprzyjała rozwojowi roślin oraz zasiedlaniu ich przez szkodniki.

W 2012 roku począwszy od kwietnia do pierwszej połowy maja zanotowano stosunkowo dużą liczbę dni z dość niskimi temperaturami (zwłaszcza noca), które początkowo ograniczały intensywny wzrost roślin. Od drugiej połowy maja wyraźny wzrost temperatury sprzyjał rozwojowi roślin. Pod względem opadów rok 2012 należał do stosunkowo suchych, jednak nie odnotowano w rejonie badań objawów niedoboru wilgoci na roślinach zbóż.

Przeprowadzone analizy roślin oraz bezpośrednie obserwacje na pszenicy jarej wykazały występowanie szkodników, takich jak: mszyce (Aphididae), skrzypionki (Oulema spp.), niezmiarka paskowana (Chlorops pumilionis Bjerk.), pryszczarkowate (Cecidomyiidae) oraz wciornastki (Thysanoptera). W latach badań, w dużym 
nasileniu występowały skrzypionki oraz niezmiarka paskowana, w średnim - mszyce i w słabym - przylżeńce, a inne owady w bardzo słabym nasileniu. W niektóre lata roślinom pszenicy oprócz skrzypionek mogą zagrażać również mszyce, miniarki, niezmiarka paskowana, ploniarka zbożówka oraz pryszczarkowate, co potwierdziły badania przeprowadzone $\mathrm{w}$ różnych regionach Polski (Beiger 1989; Jańczak i wsp. 1990; Wałkowski i Złotkowski 2000; Mrówczyński i wsp. 2007; Kaniuczak 2008; Roik i wsp. 2011).

Skuteczność biologiczną wybranych insektycydów $\mathrm{i}$ ich wpływ na plon ziarna pszenicy jarej przedstawiono w tabeli 2.

W 2011 roku uszkodzenie powierzchni liści pszenicy w obiekcie kontrolnym wynosiło średnio 51,1\%. Każda z zastosowanych w doświadczeniu kombinacji ochronnych przyczyniła się do istotnego względem kontroli (bez ochrony) ograniczenia stopnia ich uszkodzenia. Użyte insektycydy wykazały dobrą skuteczność wynoszącą od 58,5 do $94,1 \%$. Uratowany plon ziarna pszenicy w stosun- ku do kontroli na badanych obiektach wyniósł średnio 2,6 dt/ha (4,8\%). Masa 1000 ziaren (MTZ) na obiektach chronionych była wyższa względem obiektu kontrolnego, ale nie różniła się od niej istotnie.

Uszkodzenie powierzchni liści pszenicy w 2012 roku było stosunkowo wysokie $\mathrm{w}$ okresie prowadzonych badań i wynosiło $68,0 \%$. Zastosowane do ochrony insektycydy w znacznym stopniu ograniczyły uszkodzenie liści, a ich skuteczność wyniosła od 36,7 do 91,4\%. Uratowany plon ziarna pszenicy w stosunku do kontroli był wyższy i wyniósł średnio 3,0 dt/ha (5,7\%). Masa 1000 ziaren na obiektach chronionych była wyższa od kontroli, ale nie różniła się istotnie.

Ekonomiczne efekty zastosowania insektycydów $\mathrm{w}$ ochronie przed skrzypionkami w pszenicy jarej podano w tabeli 3.

Wartość plonu uratowanego w 2011 r. wyniosła od 85 do $399 \mathrm{PLN} /$ ha, średnio było to 219,5 PLN/ha. Koszt ochrony insektycydowej na 1 ha kształtował się na poziomie od 87 do 1267 PLN/ha.

Tabela 1. Przebieg warunków pogodowych w Boguchwale, latach 2011-2012

Table 1. Weather conditions in 2011-2012, in Boguchwała

\begin{tabular}{|c|c|c|c|c|c|}
\hline \multirow[t]{2}{*}{$\begin{array}{l}\text { Miesiąc } \\
\text { Month }\end{array}$} & \multirow[t]{2}{*}{$\begin{array}{l}\text { Dekada } \\
\text { Decade }\end{array}$} & \multicolumn{2}{|c|}{$\begin{array}{c}\text { Srednia temperatura powietrza } \\
\text { Mean air temperature } \\
{\left[{ }^{\circ} \mathrm{C}\right]} \\
\end{array}$} & \multicolumn{2}{|c|}{$\begin{array}{c}\text { Suma opadów } \\
\text { Rainfall sum } \\
{[\mathrm{mm}]}\end{array}$} \\
\hline & & 2011 & 2012 & 2011 & 2012 \\
\hline \multirow{4}{*}{$\begin{array}{l}\text { Kwiecień } \\
\text { April }\end{array}$} & I & 9,5 & 4,8 & 16,0 & 15,5 \\
\hline & II & 8,1 & 9,6 & 12,7 & 6,2 \\
\hline & III & 13,1 & 14,8 & 21,3 & 4,4 \\
\hline & $\begin{array}{c}\text { średnia/suma miesięczna } \\
\text { mean/sum monthly }\end{array}$ & 10,2 & 9,7 & 50,0 & 26,1 \\
\hline \multirow{4}{*}{$\begin{array}{l}\text { Maj } \\
\text { May }\end{array}$} & $\mathrm{I}$ & 9,2 & 15,3 & 20,6 & 24,3 \\
\hline & II & 15,0 & 12,3 & 9,6 & 30,1 \\
\hline & III & 17,5 & 16,7 & 19,0 & 1,6 \\
\hline & \begin{tabular}{|c|} 
średnia/suma miesięczna \\
mean/sum monthly
\end{tabular} & 13,9 & 14,7 & 49,2 & 56,0 \\
\hline \multirow{4}{*}{$\begin{array}{l}\text { Czerwiec } \\
\text { June }\end{array}$} & $\mathrm{I}$ & 19,6 & 15,8 & 29,2 & 43,8 \\
\hline & II & 17,4 & 19,6 & 23,2 & 31,4 \\
\hline & III & 17,2 & 19,7 & 36,1 & 8,4 \\
\hline & $\begin{array}{c}\text { średnia/suma miesięczna } \\
\text { mean/sum monthly }\end{array}$ & 18,1 & 18,3 & 88,5 & 83,6 \\
\hline \multirow{4}{*}{$\begin{array}{l}\text { Lipiec } \\
\text { July }\end{array}$} & I & 16,5 & 24,8 & 96,5 & 6,1 \\
\hline & II & 18,8 & 18,3 & 82,2 & 20,1 \\
\hline & III & 17,3 & 20,8 & 55,1 & 27,3 \\
\hline & $\begin{array}{c}\text { średnia/suma miesięczna } \\
\text { mean/sum monthly }\end{array}$ & 17,6 & 21,3 & 233,8 & 53,5 \\
\hline \multirow{4}{*}{$\begin{array}{l}\text { Sierpień } \\
\text { August }\end{array}$} & $\mathrm{I}$ & 18,2 & 21,6 & 15,7 & 2,6 \\
\hline & II & 19,04 & 16,5 & 12,9 & 35,3 \\
\hline & III & 21,5 & 18,9 & 0,7 & 18,4 \\
\hline & $\begin{array}{c}\text { średnia/suma miesięczna } \\
\text { mean/sum monthly }\end{array}$ & 19,5 & 19,0 & 29,3 & 56,3 \\
\hline
\end{tabular}


Tabela 2. Wpływ chemicznej ochrony na uszkodzenie roślin i plon ziarna pszenicy jarej w latach 2011-2012

Table 2. The influence of chemical protection on plant infestation and grain yield spring wheat in 2011-2012

\begin{tabular}{|c|c|c|c|c|c|c|c|c|}
\hline \multirow{3}{*}{$\begin{array}{l}\text { Lp. } \\
\text { No. }\end{array}$} & \multirow{3}{*}{$\begin{array}{c}\text { Insektycydy - faza } \\
\text { wzrostu } \\
\text { Insecticide - growth stage } \\
\text { BBCH 45-49 }\end{array}$} & \multirow{3}{*}{$\begin{array}{l}\text { Dawka } \\
\text { Dose } \\
{[1 / \text { ha }]}\end{array}$} & \multicolumn{2}{|c|}{ Skrzypionki-Oulema spp. } & \multirow{3}{*}{$\begin{array}{c}\mathrm{MTZ} \\
{[\mathrm{g}]}\end{array}$} & \multicolumn{3}{|c|}{ Plon - Yield } \\
\hline & & & \multirow{2}{*}{\begin{tabular}{|c|}
$\%$ uszkodzenia \\
blaszek liściowych \\
przez larwy \\
skrzypionek \\
$\%$ of damaged leaf \\
blades by leaf beetle \\
larve
\end{tabular}} & \multirow{2}{*}{$\begin{array}{c}\text { skuteczność } \\
\text { effectiveness } \\
{[\%]}\end{array}$} & & \multirow[b]{2}{*}{ [dt/ha] } & \multicolumn{2}{|c|}{$\begin{array}{c}\text { plon uratowany } \\
\text { yield save }\end{array}$} \\
\hline & & & & & & & [dt/ha] & {$[\%]$} \\
\hline \multicolumn{9}{|c|}{2011} \\
\hline 1. & kontrola - control & - & 51,1 & - & 35,54 & 53,9 & - & - \\
\hline 2. & Karate Zeon 050 CS & 0,1 & 3,0 & 94,1 & 35,08 & 58,6 & 4,7 & 8,7 \\
\hline 3. & Sumi-Alpha 050 EC & 0,25 & 5,1 & 90,1 & 35,27 & 56,1 & 2,2 & 4,1 \\
\hline 4. & Fastac $100 \mathrm{EC}$ & 0,1 & 13,4 & 73,7 & 36,06 & 57,1 & 3,2 & 6,0 \\
\hline 5. & Biospin $120 \mathrm{SL}$ & 1,5 & 11,0 & 78,4 & 35,23 & 55,9 & 2,0 & 3,8 \\
\hline 6. & $\begin{array}{l}\text { NeemSAzal } \\
+ \text { Trifolio S-Forte }\end{array}$ & 2,5 & 19,4 & 62,0 & 34,80 & 54,9 & 1,0 & 1,8 \\
\hline 7. & Novodor SC & 5,0 & 21,2 & 58,5 & 35,08 & 56,4 & 2,4 & 4,5 \\
\hline \multicolumn{2}{|c|}{ NIR $(0,05)-\operatorname{LSD}(0.05)$} & & 10,46 & & 1,70 & 5,17 & - & - \\
\hline \multicolumn{9}{|c|}{2012} \\
\hline 1. & kontrola - control & - & 68,0 & - & 35,86 & 54,1 & - & - \\
\hline 2. & Karate Zeon $050 \mathrm{SC}$ & 0,1 & 5,8 & 91,4 & 35,87 & 57,9 & 3,8 & 7,0 \\
\hline 3. & Sumi-Alpha 050 EC & 0,25 & 8,2 & 87,9 & 36,02 & 59,1 & 5,0 & 9,2 \\
\hline 4. & Fastac $100 \mathrm{EC}$ & 0,1 & 5,6 & 91,7 & 36,35 & 61,2 & 7,1 & 13,1 \\
\hline 5. & Biospin $120 \mathrm{SC}$ & 1,5 & 28,4 & 58,3 & 36,20 & 54,9 & 0,8 & 1,5 \\
\hline 6. & $\begin{array}{l}\text { NeemSAzal } \\
+ \text { Trifolio S-Forte }\end{array}$ & 2,5 & 29,0 & 57,3 & 36,75 & 55,3 & 1,1 & 2,1 \\
\hline 7. & Novodor SC & 5,0 & 43,1 & 36,7 & 36,11 & 54,7 & 0,6 & 1,2 \\
\hline \multicolumn{2}{|c|}{ NIR $(0,05)-\operatorname{LSD}(0.05)$} & & 8,33 & & 2,16 & 2,12 & - & - \\
\hline
\end{tabular}

MTZ - masa tysiąca ziaren - thousand seed weight

Tabela 3. Efektywność ekonomiczna insektycydów w zwalczaniu larw skrzypionek w pszenicy jarej w latach 2011-2012

Table 3. Economic efficiency of insecticides control of Oulema spp. larve in spring wheat in 2011-2012

\begin{tabular}{|c|c|c|c|c|c|c|c|}
\hline \multirow[t]{2}{*}{$\begin{array}{l}\text { Lp. } \\
\text { No. }\end{array}$} & \multirow{2}{*}{$\begin{array}{c}\text { Insektycydy - faza wzrostu } \\
\text { Insecticide - growth stage } \\
\text { BBCH 47-49 }\end{array}$} & \multirow{2}{*}{$\begin{array}{c}\text { Koszt ochrony } \\
\text { insektycydowej } \\
\text { Cost } \\
\text { of protection } \\
{[\text { PLN/ha] }}\end{array}$} & \multicolumn{2}{|c|}{$\begin{array}{l}\text { Plon uratowany } \\
\text { Yield save }\end{array}$} & \multicolumn{3}{|c|}{$\begin{array}{l}\text { Wskaźnik } \\
\text { Coefficients }\end{array}$} \\
\hline & & & [dt/ha] & [PLN/ha] & $\mathrm{W}_{\mathrm{pk}}$ & $E_{1}$ & $\mathrm{E}_{2}$ \\
\hline 1 & 2 & 3 & 4 & 5 & 6 & 7 & 8 \\
\hline \multicolumn{8}{|c|}{2011} \\
\hline 1. & Karate Zeon 050 CS & 89 & 4,7 & 399 & 4,4 & 1,0 & 1,7 \\
\hline 2. & Sumi-Alpha 050 EC & 87 & 2,2 & 187 & 2,1 & 1,0 & 1,8 \\
\hline 3. & Fastac $100 \mathrm{EC}$ & 87 & 3,2 & 272 & 3,1 & 1,0 & 1,8 \\
\hline 4. & Biospin $120 \mathrm{SL}$ & 1267 & 2,0 & 170 & 0,1 & 14,9 & 26,6 \\
\hline 5. & $\begin{array}{l}\text { NeemSAzal } \\
+ \text { Trifolio S-Forte }\end{array}$ & 735 & 1,0 & 85 & 0,1 & 8,6 & 15,7 \\
\hline 6. & Novodor SC & 420 & 2,4 & 204 & 0,5 & 4,9 & 8,7 \\
\hline \multicolumn{2}{|c|}{ Średnio - Mean } & 447,5 & 2,0 & 219,5 & 1,7 & 5,2 & 9,4 \\
\hline \multicolumn{8}{|c|}{2012} \\
\hline 1. & Karate Zeon 050 SC & 89 & 3,8 & 323 & 3,6 & 1,0 & 1,8 \\
\hline 2. & Sumi-Alpha 050 EC & 87 & 5,0 & 425 & 4,8 & 1,0 & 1,7 \\
\hline
\end{tabular}




\begin{tabular}{c|l|c|c|c|c|c|c}
\hline \multicolumn{1}{|c|}{2} & 3 & 4 & 5 & 6 & 7 & 8 \\
\hline 3. & Fastac 100 EC & 87 & 7,1 & 603 & 6,9 & 1,0 & 1,6 \\
\hline 4. & Biospin 120 SC & 1267 & 0,8 & 68 & 0,1 & 14,9 & 27,1 \\
\hline 5. & $\begin{array}{l}\text { NeemSAzal } \\
+ \text { Trifolio S-Forte }\end{array}$ & 735 & 1,1 & 93 & 0,1 & 8,6 & 16,5 \\
\hline 6. & Novodor SC & 420 & 0,6 & 51 & 0,1 & 4,9 & 9,0 \\
\hline
\end{tabular}

$\mathrm{W}_{\mathrm{pk}}$ - wskaźnik pokrycia kosztów - cost covering ratio

$\mathrm{E}_{1}$ - wskaźnik opłacalności zabiegów - treatment profitability index

$\mathrm{E}_{2}$ - procentowy wskaźnik kosztów - percentage index of the costs

Wskaźnik pokrycia kosztów wyniósł średnio 1,7. Wskaźnik ten dla niektórych kombinacji ochronnych był mniejszy od jedności, a to oznacza, że zabiegi te były nieopłacalne.

Wskaźnik opłacalności zabiegów $\left(\mathrm{E}_{1}\right)$ wyniósł od 1,0 do 14,9; średnio 4,7. Procentowy wskaźnik kosztów $\left(E_{2}\right)$ wahał się w pszenicy jarej od 1,7 do 26,6; średnio 9,4.

Wartość plonu uratowanego w 2012 r., w pszenicy jarej wyniosła od 51 do 603 średnio 260 PLN/ha. Koszt ochrony hektara plantacji pszenicy przeciw larwom skrzypionek wahał się od 87 do 1267 PLN/ha.

Wskaźnik pokrycia kosztów określający stosunek wartości produkcji uratowanego plonu do kosztów zabiegu w pszenicy jarej wyniósł od 0,1 do 6,9 ; średnio 2,6. Wskaźnik (E) był niższy od jedności dla trzech kombinacji insektycydowych (Novodor SC, Biospin 120 SC i NeemSAzal + Trifolio S-Forte), a to oznacza, że zabiegi na tych obiektach były nieopłacalne ekonomicznie.

Wskaźnik opłacalności zabiegów określający liczbę kwintali produktu chronionego równoważącego koszty ochrony roślin wyniósł od 1,0 do 14,9; średnio 5,2. Procentowy wskaźnik kosztów w pszenicy jarej wahał się od 1,6 do 27,1; średnio 9,4.

W okresie prowadzonych badań uzyskano wzrost wartości plonu uratowanego ziarna pszenicy, ale nie w każdym roku pozwolił on pokryć koszty ochrony i zapewnić zysk. W 2012 r. wyliczone wskaźniki pokrycia kosztów na obiektach, na których zastosowano Novodor SC, Biospin 120 SC i NeemSAzal + Trifolio S-Forte osiagnęły stosunkowo niską wartość poniżej jedności. Wysokie wskaźniki opłacalności zabiegów na analizowanych obiektach, sygnalizują coraz mniej korzystną relację pomiędzy kosztami ochrony (wysoka cena niektórych insektycydów) a ceną zbytu ziarna pszenicy, co potwierdzają wcześniejsze badania niektórych autorów (Juszczak i Krasiński 1998; Kaniuczak 2000).
Koszty ochrony roślin zależą od nasilenia agrofagów na prowadzonych plantacjach, od doboru środków ochrony roślin i liczby zabiegów wykonanych na plantacjach (Falger i wsp. 2009).

Według wielu badań wykonanych przez różnych autorów (Jańczak i wsp. 1990; Kaniuczak 1997, 2000, 2008; Kaniuczak i Matłosz 1999; Kurowski i Hruszka 2004) zastosowanie właściwej ochrony zbóż, odpowiednio dobrany termin zabiegu, a także skuteczne insektycydy zapewniają znaczną zwyżkę plonu oraz poprawę parametrów ziarna (MTZ).

\section{Wnioski / Conclusions}

1. W Polsce południowo-wschodniej zasiewy pszenicy uszkadzane są przez wiele fitofagów. W latach badań larwy skrzypionki stanowiły duże zagrożenie dla pszenicy uszkadzając w wysokim procencie powierzchnię blaszek liściowych.

2. Warunki pogodowe w poszczególnych latach badań różnicujące stopień uszkodzenia roślin przez larwy skrzypionek wpływały na produkcyjną i ekonomiczną efektywność stosowania zabiegów nalistnej ochrony roślin. Użycie insektycydów w uprawie pszenicy jarej powodowało uratowanie plonu ziarna średnio o 5,2\% w stosunku do obiektu kontrolnego.

3. Wskaźnik pokrycia kosztów w przypadku stosowania insektycydów wahał od 0,1 do 6,9 w zależności od warunków pogodowych w poszczególnych latach badań.

4. Stosowanie insektycydów sprawia, że koszty ochrony są niskie, w konsekwencji czego wskaźnik opłacalności wyrażający ilość plonu równoważącą koszty zabiegu jest stosunkowo niski.

\section{Literatura / References}

Adamczewski K., Matysiak K. 2002. Zboża. s. 15-19. W: „Klucz do określania faz rozwojowych roślin jedno- i dwuliściennych w skali BBCH". ["Compendium of Growth Stage Identification Keys for Mono- and Dicotyledonous Plants"] (K. Adamczewski, K. Matysiak - thumaczenie i adaptacja). Wyd. I, Inst. Ochr. Roślin, Poznań, 134 ss.

Beiger M. 1989. Miniarki (Agromyzidae) - szkodniki roślin użytkowych. Wyd. Nauk. Uniwersytetu im. A. Mickiewicza, Poznań, 155 ss.

Bubniewicz P., Walczak F., Mrówczyński M., Widerski K., Kaniuczak Z. 1993. Skrzypionki występowanie w zbożach i ich zwalczanie. Instrukcja upowszechnieniowa. Inst. Ochr. Roślin, Poznań, 19 ss.

Falger P., Mrówczyński M., Jaworski R., Marcinkowski J., Grudzień-Kozaczka L. 2009. Efektywność ekonomiczna produkcji roślin rolniczych z uwzględnieniem kosztów ochrony roślin. [Economic efficiency of agricultural production considering the cost of plant protection]. Prog. Plant Prot./Post. Ochr. Roślin 49 (4): 1588-1595. 
Golinowska M. 2009. Ekonomika ochrony roślin w teorii i praktyce. [Economics of plant protection in theory and practice]. Prog. Plant Prot./Post. Ochr. Roślin 49 (1): 23-33.

Jańczak C., Pokacka Z., Ruszkowska M., Wachowiak M. 1990. Chemiczna ochrona zbóż przed chorobami i szkodnikami. Instrukcja upowszechnieniowa. Inst. Ochr. Roślin, Poznań, 41ss.

Juszczak M., Krasiński T. 1998. Ekonomiczna ocena ochrony pszenicy ozimej i rzepaku ozimego. [Economic estimation of winter wheat and winter rape protection]. Prog. Plant Prot./Post. Ochr. Roślin 38 (1): 247-257.

Kaniuczak Z. 1987. Skrzypionki (Oulema spp.) - narastające zagrożenie plonów zbóż w Polsce. Materiały 27. Sesji Nauk. Inst. Ochr. Roślin, cz. 2: 61-65.

Kaniuczak Z. 1993. Badania nad występowaniem, przebiegiem rozwoju, szkodliwością i zwalczaniem skrzypionek (Oulema spp.) w uprawie pszenicy ozimej w południowo-wschodniej Polsce. Prace Nauk. Inst. Ochr. Roślin 33 (1/2): 9-55.

Kaniuczak Z. 1997. Noxiousness and control of Oulema spp. larvae in the spring wheat. J. Plant Prot. Res. 37 (1/2): 99-103.

Kaniuczak Z. 2000. Wpływ chemicznej ochrony roślin na plonowanie pszenicy. [Influence of chemical protection on field of wheat]. Prog. Plant Prot./Post. Ochr. Roślin 40 (2): 488-491.

Kaniuczak Z. 2008. Distribution and effects of chemical control of gout fly (Chlorops pumilionis Bjerk.) on spring wheat in southeastern Poland. J. Plant Prot. Res. 48 (4): 453-460.

Kaniuczak Z. 2011. Occurrence band range damage on wheat and spring triticale cultivars caused by gout fly (Chlorops pumilionis Bjerk.) in south-eastern Poland. Acta Sci. Pol., Agricultura 10 (4): 97-106

Kaniuczak Z., Bereś P. 2008. Najważniejsze szkodniki zbóż w gospodarstwach ekologicznych Polski południowo-wschodniej. J. Res. Appl. Agric. Engin. 53 (3): 128-132.

Kaniuczak Z., Lisowicz F. 1992. Dynamika populacji oraz efekty zwalczania mszyc (Aphididae) w uprawie pszenicy ozimej w południowo-wschodniej Polsce. Prace Nauk. Inst. Ochr. Roślin 34 (1/2): 93-98.

Kaniuczak Z., Lisowicz F., Śnieżek G. 1992. Metody sygnalizacji terminów zwalczania i progi zagrożenia najważniejszych chorób i szkodników pszenicy w warunkach Polski południowo-wschodniej. Materiały 32. Sesji Nauk. Inst. Ochr. Roślin, cz. 2: 22-29.

Kaniuczak Z., Matłosz I. 1999. Efekty produkcyjne i ekonomiczne zwalczania szkodników w zbożach. Pam. Puł. 114: 159-165.

Kurowski T.P., Hruszka M. 2004. Zdrowotność i plonowanie pszenżyta ozimego w łanie chronionym zabiegami chemicznymi i proekologicznymi. [Effects of the economical profotability of chemical control of pests in cereals]. Prog. Plant Prot./Post. Ochr. Roślin 44 (2): 896-899.

Lipa J.J. 1999. Nowoczesna ochrona zbóż. Pam. Puł. 114: 241-259.

Miczulski B. 1973. Studies on the bionomics of Oulema spp. (Coleoptera, Chrysomelidae) in Poland. Rocz. Nauk Rol., Seria E, Ochrona Roślin 3: 61-86.

Miętkiewski R., Żurek M., Stankiewicz C., Starczewski J. 1991. Występowanie wciornastków (Thysanoptera) w kłosach żyta, pszenicy i pszenżyta oraz wpływ ich żerowania na niektóre właściwości fizjologiczne i skład chemiczny ziarna. Zesz. Nauk. WSR-P Siedlce, Seria Rolnictwo 29: 187-200.

Mrówczyński M., Kaniuczak Z., Bereś P., Pruszyński G., Bubniewicz P., Wachowiak H. 2007. Podręczny atlas szkodników pszenicy. Plantpress, Kraków, 63 ss.

Mrówczyński M., Wachowiak H., Boroń M. 2005. Szkodniki zbóż - aktualne zagrożenia w Polsce. [Cereals pests - current threats in Poland]. Prog. Plant Prot./Post. Ochr. Roślin 45 (2): 929-932.

Roik K., Walczak F., Bandyk A., Kubsik K. 2011. Uszkodzenia powodowane przez muchówki z rodziny Agromyzidae na wybranych plantacjach pszenicy ozimej w Wielkopolsce. [Damages caused by leaf miners flies (Agromyzidae) on winter wheat plantations in Wielkopolska]. Prog. Plant Prot./Post. Ochr. Roślin 51 (2): 609-613.

Wałkowski W., Złotkowski J. 2000. Możliwości jednoczesnego zwalczania skrzypionek i mszyc w zbożach. [Possibility of simultaneous control of cereal leaf beatles and aphids in cereal crops]. Prog. Plant Prot./Post. Ochr. Roślin 40 (2): $483-487$. 